\title{
NGHIÊN CỨU GIÁ TRI CỦA NộI SOI PHÓNG ĐẠI NHUỘM MÀU ẢO (FICE) VÀ NHUỘM MÀU THẦTT (CRYSTAL VIOLET) TRONG DỰ ĐOÁN KẾT QUẢ MÔ BÊ̂NH HỌC POLYP ĐẠI TRỰC TRÀNG
}

\author{
Phạm Bình Nguyên ${ }^{1}$, Vũ Trường Khanh ${ }^{1}$, Đào Văn Long ${ }^{2}$
}

\section{TÓM TẮT}

Nội soi đại trực tràng (ĐTT) là phương pháp tốt nhất cho phép phát hiện, điêuu trị polyp, giúp giảm từ $76-90 \%$ tỷ lề mắc mới ung thư ĐiT. Tuy nhiên, nội soi ánh sáng trẳng còn hạn chế trong dự đoán chính xác mô bệnh học polyp. Các kỹ thuật nội soi cải tiến đã được phát triển giúp quan sát chi tiết hơn bề mặt niêm mạc, cấu trúc mạch máu dưới niêm mạc tự đó dự đoán chính xác kết quả mô bệnh học polyp, hố trợ điều trị chính xác. Mục tiêu: Nighiên cứu nhằm đổi chiếu hình ảnh nội soi phóng đại (NSPĐ) nhuộm màu ảo (FICE) và nhuộm màu that (Crystal violet) với kết quả mô bệnh học ở bệnh nhân có polyp đại trực tràng. Phương pháp: Nghiên cứu mô tả đánh giá nghiệm pháp chẩn đoán trên tổng số 332 polyps ĐTT của 266 bệnh nhân được cắt nội soi hoặc phẫu thuật từ tháng 6/2016 đến 9/2019. Bệnh nhân được nội soi thường ĐTT phát hiện polyp. Sau đó, polyp sẽ được NSPĐ nhuôm màu ảo FICE đánh giá đắc điểm hình ảnh mạch máu niêm mạc theo Teixeira (gồm 5 typ), và NSPĐ nhuôm màu thât Crystal violet $0,05 \%$ đánh giá hình thái î̂̃ niêm mạc (pit pattern) theo phân loai Kudo. Cuối cùng, các polyp sẽ được chỉ định cắt nội soi hoặc phẫu thuật và lấy mẫu để đọc kết quả mô bệnh học (polyp tân sinh/không tân sinh̀) và đối chiếu với các phân loại theo hình ảnh nội soi. Kết quả: Trong nghiên cứu, 278/332 polyp tân sinh (231 polyp u tuyến và 47 polyp ung thư'). Các phương pháp NSPĐ nhuộm màu đều có độ nhạy, độ chính xác cao khi đối chiếu với kết quả mô bệnh học của polyp. Độ nhạy, độ đặc hiệu và độ chính xác của chẩn đoán với các polyp tẩn sinh của các phương pháp NSPĐNM Crystal violet $(97,2 \%, 72,2 \%, 93,0 \%)$, NSPĐ nhuộm màu ảo FICE $(92,1 \%, 68,5 \%$ và $88,3 \%) .24 / 332$ polyp được phân loại Kudo typ Vi, trong đó có $50 \%$ (12/24) kết quả mô bệnh học tương ứng là ung thư xâm lấn trong lớp niêm mạc, 20,8\% (5/24) có kết quả mô bệnh học là ung thư biểu mô đã xâm lấn lớp dưới niêm mạc. 23/332 polyp được phân loại Kudo typ Vn đều có kết quả mô bệnh học là ung thư, trong đó 78,3\% (18/23) là ung thư xâm lấn lớp dưới niêm mạc, 21,7\% (5/23) là ung thư xâm lấn trong lớp niêm mạc. Kết luận: Nội soi phóng đại, nhuộm màu (FICE, với Crystal violet) có khả dự đoán kết quả mô bệnh học polyp đại trực tràng với độ chính xác cao. Tư khóa: Nội soi phóng đại, polyp đại trực tràng, nội soi tăng cường màu sắc đa phổ (FICE), crystal violet.

${ }^{1}$ Khoa Tiêu Hóa, Bênh viện Bạch Mai
${ }^{2}$ Trường Đaì hoc Y Hà Nội

Chịu trách nhiệm chính: Phạm Bình Nguyên

Email: drnguyemthbm@gmail.com

Ngày nhận bài: 15.6.2021

Ngày phản biên khoa học: 10.8.2021

Ngày duyệt bài: 18.8.2021

\section{SUMMARY \\ STUDY ON VALUE OF VIRTUAL MAGNIFYING \\ CHROMOENDOSCOPY WITH (FICE) AND \\ MAGNIFYING CHROMOENDOSCOPY WITH CRYSTAL VIOLET IN PREDICTING \\ HISTOPATHOLOGY OF COLORECTAL POLYP}

Colonoscopy is the best method for detecting and treating polyps, helping to reduce the incidence of colorectal cancer by $76-90 \%$. However, white light endoscopy is limited in accurately predicting polyp histopathology. The image-enhanced endoscopy techniques have been developed to help visualize the mucosal surface and submucosal vascular structures in more detail, thereby accurately predicting polyp histopathology results, supporting accurate treatment. Objective: This study compared the images of virtual magnifying chromoendoscopy with FICE, basedstaining magnifying chromoendoscopy with Crystal violet with colorectal polyps histopathology. Methods: A descriptive study, evaluating diagnostic tests on a total of 332 polyps of 266 patients was endoscopically or surgically resected from $06 / 2016$ to $09 / 2019$. After identified by white light endoscopy, polyps continued to be evaluated by virtual magnifying chromoendoscopy (x50-150 times) with FICE. The capillary pattern was divided into 5 subtypes according to the number, morphology, and distribution of the fine blood vessels according to Teixeira classification). Then, polyps were stained in order to with Crystal violet $0.05 \%$ (according to Kudo classification for morphological characteristics of pit pattern). Finally, polyps were resected by endoscopy or surgery, biopsy and compared with histopathological results (neoplastic/non-neoplastic polyp). Results: The number of neoplastic polyps was 278/332 with 231 adenoma polyps and 47 carcinoma polyps. Magnifying chromoendoscopy has high sensitivity and accuracy when compared with the histopathological results of colorectal polyps. The sensitivity, specificity, and accuracy of magnifying chromoendoscopy with Crystal violet $(97.2 \%, 72.2 \%, 93.0 \%)$; and with FICE $(92,1 \%$, $68,5 \%, 88,3 \%) .24 / 332$ polyps were classified as Kudo type Vi, of which $50 \%$ (12/24) histopathological results were intramucosal carcinoma, 20.8\% (5/24) had histopathological results as submucosal carcinoma . 23/332 polyps classified as Kudo type Vn all had histopathological results as cancer, of which $78.3 \%$ $(18 / 23)$ were submucosal carcinoma, 21.7\% (5/23) were intramucosal carcinoma. Conclusions: The magnifying chromoendoscopy with FICE, Crystal violet is good to predict histopathological results of colorectal polyp. Keywords; magnifying chromoendoscopy, colorectal polyps, Flexible spectral imaging color enhancement (FICE), Crystal violet 


\section{I. ĐẶT VẤN ĐỀ}

Polyp đại trực tràng (ĐTT) là một bệnh lý đường tiêu hóa do sự phát triển quá mức của niêm mạc và mô dưới niêm mạc ĐTT tạo thành. Tại châu Á và châu Âu, tỷ lệ mắc polyp ĐTT lên tới $12 \%$ và $26 \%$ dân số, phát sinh bệnh có liên quan nhiều yếu tố như lối sống, giới tính, độ tuổi và di truyền [1],[2]. Polyp chia hai nhóm lớn: polyp tân sinh (polyp u tuyến ống, nhung mao, ống nhung mao, polyp răng cưa không cuống) và polyp không tân sinh (polyp viêm, polyp tăng sản, polyp thiếu niên và polyp Hamartomatous) [2]. Trong đó, polyp tân sinh có nguy cơ cao tiến triển thành ung thư ĐTT. Theo Silva S.M và cộng sự, $60 \%-90 \%$ trường hợp ung thư ĐTT phát triển từ polyp ĐTT [3]. Nội soi là phương pháp hiệu quả nhất cho phép phát hiện và điều trị polyp ĐTT giúp giảm từ $76-90 \%$ tỷ lệ mắc mới ung thư $Đ T T$.

Vấn đề tiếp theo đặt ra cho bác sỹ nội soi là sẽ dựa vào tiêu chí nào để xác định polyp tân sinh ác tính hay không để quyết định có thể cắt polyp bằng nội soi hay phẫu thuật. Hiện nay, kết quả mô bệnh học được coi là tiêu chuẩn vàng để xác định polyp tân sinh hay không tân sinh. Việc sinh thiết hoặc cắt polyp không tân sinh (như polyp tăng sản lành tính) có thể không cần thiết do tốn nhiều thời gian và có thể gây chảy máu. Mặt khác, nhiều trường hợp polyp ác tính đã xâm lấn xuống dưới lớp niêm mạc lại có hình ảnh đại thể rất giống với polyp u tuyến. Vì thế, các bác sỹ chỉ thực hiện nội soi thường để cắt polyp sẽ không loại bỏ được hoàn toàn tế bào ác tính còn ở thành ruột hoặc hạch bạch huyết. Vì vậy, việc dự đoán kết quả mô bênh học bằng nội soi sẽ giúp ích rất nhiều cho các bác sỹ nội soi trong lựa chọn phương pháp điều trị phù hợp. Hiện nay, nhiều phương pháp nội soi cải tiến mới đã được phát triển như kỹ thuật NSPĐ nhuộm màu ảo (Flexible spectral Imaging Colour Enhancement -FICE) và NSPĐ nhuộm màu thât (Crystal violet) đã giúp quan sát tốt hơn đặc điểm hình thái lỗ niêm mạc (pit pattern) và cấu trúc mạch máu niêm mạc polyp đại trực tràng. Điều này cho phép dự đoán kết quả mô bệnh học polyp đại trực tràng với độ chính xác cao, hỗ trợ lựa chon phương pháp điều trị phù hợp. Tuy nhiên, các kỹ thuật này còn chưa được nghiên cứu, đánh giá hiệu quả chẩn đoán một cách hệ thống tại Việt Nam nên chúng tôi thực hiện để tài: Nghiên cứu giá trị nội soi phóng đại, nhuộm màu ảo (FICE) và nhuộm màu thật (crystal violet) trong dự đoán mô bệnh học polyp đại trực tràng.

\section{II. ĐỐI TƯợNG VÀ PHƯƠNG PHÁP NGHIÊN CỨU}

1.Thời gian và địa điểm nghiên cứu: tháng 5/2016 - 9/2019, tại Trung tâm nội soi tiêu hóa Viêt-Nhât, Bênh viền Bach Mai.

2. Đối tượng: 266 bệnh nhân đã được nội soi thường phát hiện ĐTT phát hiện 332 polyp và đánh hình dạng theo phân loại Paris. Các polyp sau đó được được đánh giá đặc điểm cấu trúc mạch máu dưới niêm mạc, đặc điểm hình thái Iỗ niểm mạc bằng NSPĐ nhuộm màu ảo FICE và NSPĐ nhuộm màu thật Crystal violet 0,05\%.

\section{Tiêu chuẩn lựa chọ:}

- Bệnh nhân đồng ý tham gia nghiên cứu.

- Bểnh nhân có các triêuu chứng lâm sàng như đau bụng, rối loạn tiêu hóa, táo bón, phân máu và được chỉ định nội soi đại tràng có phát hiện polyp

- Bệnh nhân không có triệu chứng lâm sàng nhưng đi nội soi tầm soát ung thư ĐTT có phát hiện polyp

- Bệnh nhân chuẩn bị đại tràng sạch, mức độ sach được đánh giá theo thang điểm Boston có tổng điểm $\geq 8$

\section{Tiêu chuẩn loai trừ:}

- Bệnh nhân có chống chỉ định nội soi đại tràng toàn bộ: suy tim nặng, suy hô hấp nặng, tình trạng sốc, $\ldots$

- Bềnh nhân nội soi đại tràng có polyp nhưng bề mặt polyp bám nhiều chất nhày không thể làm sạch.

- Bệnh nhân không sinh thiết được polyp hoặc không cắt được hết polyp qua nội soi.

- Những bệnh nhân có rất nhiều polyp đại trực tràng mà chúng tôi không thể đủ thời gian để đánh giá được tất cả các polyp bằng phương pháp NSPĐ, nhuộm màu. Vì vậy, chúng tôi loại khỏi nghiên cứu các bệnh nhân có $\geq 4$ polyp

- Bệnh nhân không đờng ý tham gia nghiên cứu.

3. Thiết kế nghiên cứu: Thiết kế nghiên cứu mô tả đánh giá nghiệm pháp chẩn đoán

Cõ̃ mẫu tính toán độ nhạy cho nghiên cứu đánh giá nghiệm pháp chẩn đoán :

$$
\begin{aligned}
& n_{s e} \frac{T P+F N}{p_{\text {dis }}} ; \mathrm{TP}+\mathrm{FN}= \\
& =\frac{Z_{\propto \infty}^{2} \times p_{s e} \times\left(1-p_{s e}\right)}{w^{2}} \\
& \text { Trong đó: } \\
& \text { - nse là ước tính cõ mẫu theo độ nhạy } \\
& \text { - TP + FN là số dương tính thật (True } \\
& \text { Positive) và âm tính giả (False Negative) } \\
& \text { - pdis: tỷ lệ polyp ĐTT } \\
& \text { - pse: là độ nhạy của phương pháp trong }
\end{aligned}
$$


chẩn đoán polyp ĐTT

- Za: là hằng số của phân phối chuẩn. Với $\mathrm{a}=0,05$ thì hằng số $\mathrm{Za}=1,96$

- w là sai số 2 xác suất dương tính thật và âm tính giả (với $w=0,05$ )

- Tham khảo y văn, lấy pdis $=0,4$; độ nhạy trong chẩn đoán polyp ĐTT là $95 \%$.

- Thay vào công thức ta tính được $n=183$ bệnh nhân. Thực tế, chúng tôi đã tiến hành nghiên cứu trên 266 bệnh nhân với 332 polyp.

Thực hiện nghiên cứu:

Bước 1: Nội soi toàn bộ đại tràng, đưa đèn soi vào van Bauhin và góc hồi manh tràng

Bước 2: Trong quá trình rút ống nội soi, quan sát phát hiện các polyp đại tràng. Sau đó, polyp sẽ được rửa sạch bằng nước. Đo kích thước polyp dựa vào độ mở của kìm sinh thiết (8mm).

Bước 3: Sử dụng nút điều khiển chuyển sang chế độ NSPĐ FICE: Quan sát polyp ở chế độ FICE (kênh 4) không phóng đại và FICE có kết hợp phóng đại 50-150 lần và đánh giá polyp theo phân loại mạch máu của Teixeira

Bước 4: Phun $5-10 \mathrm{ml}$ dung dịch thuốc nhuộm Crystal violet 0,05\% phủ đều trên bề mặt polyp. Chờ $1-2$ phút cho thuốc nhuộm hấp thụ đều lên polyp. Điều chỉnh lại về chế độ ánh sáng thường với độ phóng đại 50-150 lần. Đánh giá đặc điểm hình thái lố niêm mạc (pit pattern) của polyp theo phân loại Kudo bằng ánh sáng thường và phóng đại. Đối với những trường hợp nghi ngờ polyp ung thư (FICE typ V, Kudo typ $V)$, bệnh nhân đều được sinh thiết làm giải phâuu bệnh. Sau đó chụp CT ổ bụng, X-quang phổi đánh giá thêm.

Bước 5: Cắt polyp qua nội soi/phẫu thuật

Bước 6: Lấy mâu bệnh phẩm sau cắt polyp vào ống bảo quản, ngẩm formol $10 \%$ để bảo quản và gửi tới Trung tâm giải phẫu bệnh để đọc kết quả.

Phân loại mạch máu FICE theo Teixeira:

- Nhóm polyp có phân loại FICE typ I, II: tương ứng với polyp không tân sinh

- Nhóm polyp có phân loại FICE typ III, IV, V: tương ứng với polyp tân sinh

Phân loại Kudo cho đặc điểm hình thái lỗ niêm mạc:

- Nhóm polyp có phân loại Kudo typ I, II: tương ứng với polyp không tân sinh

- Nhóm polyp có phân loại Kudo typ IIIL, IIIs, IV, Vi, Vn: tương ứng với polyp tân sinh

- A. Type I: Mô hình mạch máu dưới biểu mô niêm mạc mỏng, đều, xung quanh các nếp rãnh niêm mạc;

B. Type II: Tân sinh mạch đường kính dày hơn, cong hoặc thẳng nhưng tương đối đồng nhất, không có điểm giãn nở và sắp xếp xung quanh các hố niêm mạc không rõ ràng;

C. Type III: Tân sinh nhiều mao mạch với đường kính mỏng hơn, chạy quanh co không đều, nhiều điểm giãn nở dạng xoắn ốc, sự sắp xếp mạch máu quanh các tuyến rõ ràng;

D. Type IV: Nhiều mạch máu dài, vặn xoắn hoặc thẳng với đường kính dày hơn, có các điểm giãn nở thưa thớt, sắp xếp chạy thẳng hoặc vòng xung quanh các ống tuyến.; E. Type V: Các mao mạch đa hình thái, phân phối và sắp xếp hỗn loạn, không đồng nhất, hoặc có vùng không quan sát thấy mạch máu; nhiều mạch dày; có khi mất cấu trúc mạch.
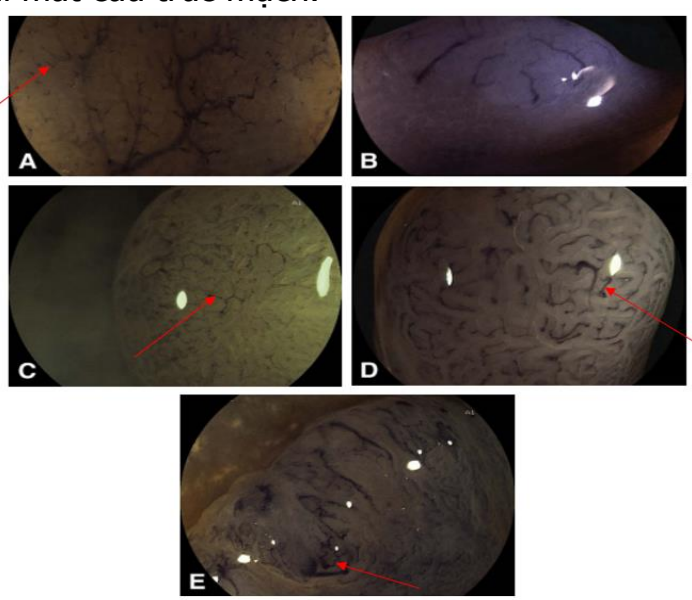

Hình 1. Hệ thống phân loại mạch máu dưới niêm mạc (Theo Teixeira CR và CS) [4]

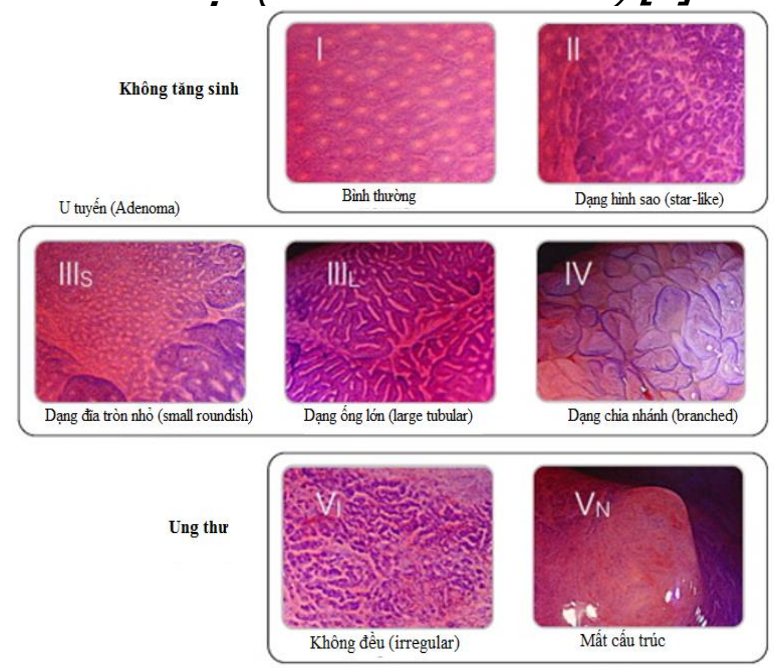

Hình 2. Phân loại Kudo phân loại hình thái lỗ niêm mạc trong NSPĐ nhuộm màu Crystal violet (Theo Kobayashi và cs) [5]

Tất cả các tổn thương được quan sát bởi NSPĐ đều hoặc được sinh thiết và đánh giá mô 
bệnh học theo phân loại Tổ chức $Y$ tế Thễ giới năm 2010 đọc tại Khoa Giải phẫu bệnh, bệnh viện Trung ương Quân đội 108.

4. Nhập và xử lý số liệu: Số liệu được nhập, quản lý bằng phần mềm EPIDATA 3.1 và được làm sạch, phân tích bằng phần mềm thống kê STATA 12.0.

Biến số định lượng được biểu diễn dưới dạng số trung bình, độ lệch chuẩn. Biến số định tính được biểu diễn dưới dạng tần số, tỷ lệ \%.

Kiểm định Khi bình phương (X2 test), Fisher's exact test đánh giá sự khác biệt tỷ lệ của trên 1 nhóm. Kết quả kiểm định có ý nghĩa với giá trị $\mathrm{p}<0,05$.

Tính độ nhạy, độ đặc hiệu, giá trị chẩn đoán dương tính, giá trị chẩn đoán âm tính và độ chính xác của phương pháp NSPĐ nhuộm màu ảo FICE, nhuộm màu thật Cystal violet 0,05\%.

5. Đạo đức nghiên cứu: Các đối tượng tự nguyện tham gia nghiên cứu, mọi thông tin đảm bảo bí mật.

\section{KẾT QUẢ NGHIÊN CỨU}

\subsection{Thông tin chung}

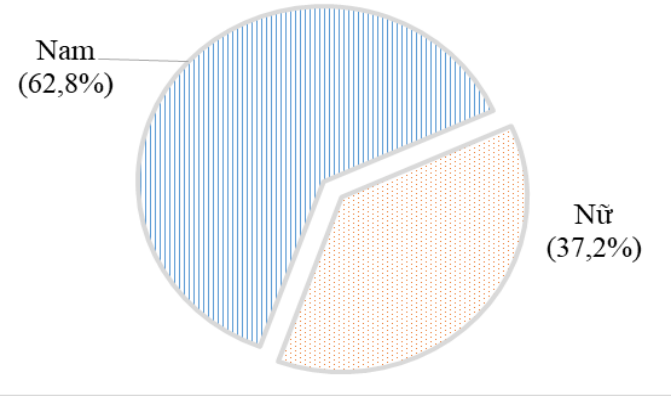

Biểu đồ 1. Phân bố bệnh nhân nghiên cứu theo giới tính $(n=266)$

Nhận xét: Theo phân bố giới tính, số lượng bệnh nhân là nam giới chiếm tỷ lệ cao nhất với 167/266 bênh nhân (tương ứng với 62,8\%), nữ giới chiếm tỷ lệ thấp hơn với $37,2 \%$, Tỷ sô nam/nữ $=167 / 99=1,7$ lần.

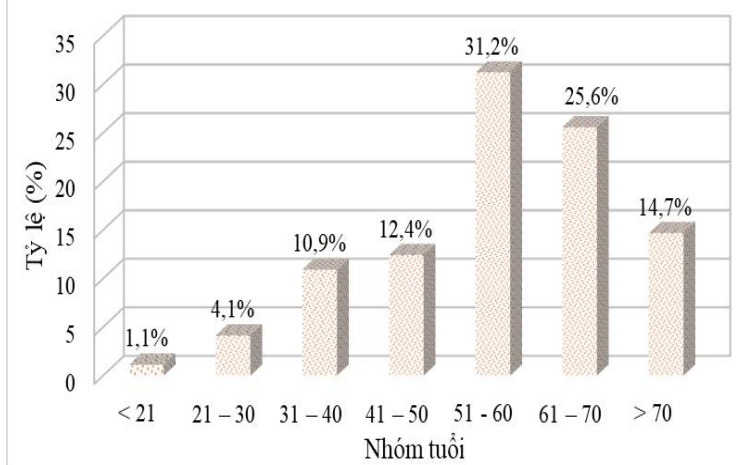

Biểu đồ 2. Đăc điểm bênh nhân mắc polyp ĐTT theo nhóm tuôii $(n=266)$

Nhânn xét: Theo phân bố giới tính, số lượng bênh nhân là nam giới chiếm tỷ lê cao nhất với 167/266 bệnh nhân (tương ứng với 62,78\%), nũ giới chiếm tỷ lệ thấp hơn với $37,22 \%$, Tỷ số nam/nữ $=167 / 99=1,7$ lần.

Phân theo nhóm tuổi, đa số bệnh nhân thuộc nhóm tuổi trên 50 tuổi chiếm tỷ lệ 71,43\%, trong khi đó nhóm tuổi dưới 50 có tỷ lệ bệnh nhân mắc polyp đại trực tràng thấp hơn, chiếm $28,57 \%$.

3.2. Đối chiếu hình ảnh NSPĐ nhuộm màu ảo FICE, NSPĐ nhuộm màu thật Crystal violet $0,05 \%$ với kết quả mô bệnh học

Bảng 1. Môi liên quan giữa phân loại mạch máu theo Teixeira bằng NSPĐ FICE và mô bệnh họ

\begin{tabular}{|c|c|c|c|c|c|c|}
\hline \multirow{4}{*}{$\begin{array}{c}\text { Phân } \\
\text { loại } \\
\text { Teixeira } \\
\text { (FICE) }\end{array}$} & \multicolumn{5}{|c|}{ Kêt quả mô bệnh học } & \multirow{4}{*}{ Tổng } \\
\hline & \multirow{3}{*}{\begin{tabular}{|c|}
$\begin{array}{c}\text { Polyp không } \\
\text { tân sinh }\end{array}$ \\
$\begin{array}{c}\text { Tăng sản lành } \\
\text { tính/thiếu niên }\end{array}$
\end{tabular}} & \multicolumn{4}{|c|}{ Polyp tân sinh } & \\
\hline & & \multicolumn{2}{|c|}{ Polyp u tuyến } & \multicolumn{2}{|c|}{ Ung thu' } & \\
\hline & & $\begin{array}{l}\text { Loạn sản } \\
\text { độ thấp }\end{array}$ & $\begin{array}{c}\text { Loạn sản } \\
\text { độ cao }\end{array}$ & $\begin{array}{l}\text { Trong lớp } \\
\text { niêm mạc }\end{array}$ & $\begin{array}{c}\text { Xâm lấn lớp } \\
\text { dưới niêm mạc }\end{array}$ & \\
\hline Typ II & 3 & $22(37,3)$ & & $0(0,0)$ & $0(0,0)$ & $59(17,8)$ \\
\hline Typ III & 17( & $125(81,2)$ & & $2(1$ & $, 0)$ & $154(46,4)$ \\
\hline Typ IV & $0(0,0)$ & $36(44,4)$ & $33(40,7)$ & $7(8,6)$ & $5(6,2)$ & $81(24,4)$ \\
\hline Typ V & $0(0,0)$ & $0(0,0)$ & $5(13,2)$ & $13(34,2)$ & $20(52,6)$ & $38(11,4)$ \\
\hline Tống & $54(16,3)$ & $183(55,1)$ & $48(14,5)$ & $22(6,6)$ & $25(7,5)$ & $332(100,0)$ \\
\hline
\end{tabular}

Nhân xét: Nhóm FICE typ II, $22 / 59$ (37,3\%) polyp u tuyến, không có polyp ung thư. Nhóm FICE typ III, $135 / 154(87,7 \%)$ polyp u tuyến, $2 / 154$ (1,3\%) polyp ung thư. Nhóm FICE typ IV, 69/81 $(85,1 \%)$ là polyp u tuyến, $12 / 81(14,8 \%)$ polyp ung thư. Nhóm FICE typ $V, 5 / 38(13,2 \%)$ polyp u tuyến, $33 / 38(86,8 \%)$ polyp ung thư.

Bảng 2. Mối quan hê giữa phân loại Kudo hình thái lỗ tuyến niêm mạc trong NSPĐ nhuộm Crystal violet và mô bệnh học 


\begin{tabular}{|c|c|c|c|c|c|c|}
\hline \multirow{4}{*}{$\begin{array}{c}\text { Phân } \\
\text { loại } \\
\text { Kud̃o }\end{array}$} & \multicolumn{5}{|c|}{ Kết quả mô bệnh học } & \multirow{4}{*}{ Tổng } \\
\hline & \multirow{3}{*}{$\begin{array}{c}\begin{array}{c}\text { Polyp không } \\
\text { tân sinh }\end{array} \\
\text { Tăng sản lành } \\
\text { tính }\end{array}$} & \multicolumn{4}{|c|}{ Polyp tân sinh } & \\
\hline & & \multicolumn{2}{|c|}{ Polyp u tuyến } & \multirow[b]{2}{*}{$\begin{array}{l}\text { Trong } \\
\text { lớp NM }\end{array}$} & \multirow[b]{2}{*}{$\begin{array}{l}\text { Xâm lấn lớp } \\
\text { dưới niêm mạc }\end{array}$} & \\
\hline & & $\begin{array}{l}\text { Loạn sản } \\
\text { đố thấp }\end{array}$ & $\begin{array}{l}\text { Loạn sản } \\
\text { đố cao }\end{array}$ & & & \\
\hline II & $39(83,0)$ & $8(17,0)$ & $0(0,0)$ & $0(0,0)$ & $0(0,0)$ & $47(14,2)$ \\
\hline IIIL & $15(9,0)$ & $144(86,2)$ & $7(4,2)$ & $1(0,6)$ & $0(0,0)$ & $167(50,3)$ \\
\hline IIIs & $0(0,0)$ & $5(55,6)$ & $3(33,3)$ & $1(11,1)$ & $0(0,0)$ & $9(2,7)$ \\
\hline IV & $0(0,0)$ & $26(41,9)$ & $31(50,0)$ & $3(4,8)$ & $2(3,3)$ & $62(18,7)$ \\
\hline $\mathrm{Vi}$ & $0(0,0)$ & $0(0,0)$ & $7(29,2)$ & $12(50,0)$ & $5(20,8)$ & $24(7,2)$ \\
\hline $\mathrm{Vn}$ & $0(0,0)$ & $0(0,0)$ & $0(0,0)$ & $5(21,7)$ & $18(78,3)$ & $23(6,9)$ \\
\hline Tống & $54(16,3)$ & $183(55,1)$ & $48(14,5)$ & $22(6,6)$ & $25(7,5)$ & $332(100,0)$ \\
\hline
\end{tabular}

Nhận xét: Nhóm Kudo typ II, $8 / 47$ (17\%) polyp u tuyến, không có polyp ung thư. Nhóm Kudo typ IIIL,151/167 $(90,4 \%)$ polyp u tuyến, $1 / 167(0,6 \%)$ polyp ung thư. Nhóm Kudo typ IIIs, $8 / 9$ $(88,9 \%)$ là polyp u tuyến, $1 / 9(11,1 \%)$ polyp ung thư. Nhóm Kudo typ IV, $57 / 62(91,9 \%)$ polyp u tuyến, 5/62 (8,1\%) polyp ung thư. Nhóm polyp Kudo typ Vi, 7/24 $(29,2)$ polyp u tuyến, 17/24 $(80,8 \%)$ polyp ung thư. Trong khi đó, tất cả nhóm polyp Kudo typ Vn đều có kết quả mô bệnh học là ung thu' $(100 \%)$.

Bảng 3. Giá trị chẩn đoán phân biệt polyp tân sinh, không tân sinh của các phương pháp NSPENM trong chẩn đoán mô bệnh học polyp đại trực tràng

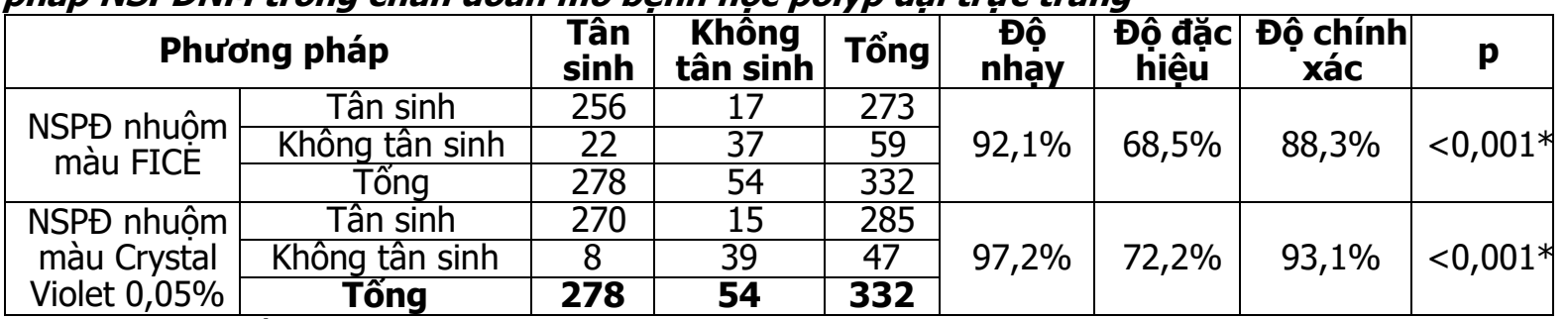

(*) Test khi bình phương

\section{BÀN LUÂ̂N}

Nghiên cứu thực hiên nội soi trên 266 bênh nhân lứa tuổi từ 17 đến 93 tuổi với đô tuổi trung bình là $56,4 \pm 14,4$. Kết quả nghiên cứu cho thấy, nam giới có tỷ lệ mắc polyp ĐTT cao hơn nữ giới với tỷ lệ nam/nữ $=1,67 / 1$, đa số bệnh nhân khám phát hiện và điêu trị ở nhóm đối tượng trên 50 tuổi $(81,4 \%)$.

Trong nghiên cứu của chúng tôi, NSPĐ FICE có độ nhạy, độ đặc hiệu, độ chính xác của chẩn đoán phân biệt polyp tân sinh/không tân sinh lần lượt là $92,1 \%, 68,5 \%$, và $88,3 \%$. Kết quả này cao hơn với nghiên cứu của Longcroft-wheaton và công sự thực hiên NSPĐ FICE để nội soi đánh giá 232 polyp kích thước dưới $10 \mathrm{~mm}$ theo phân loại mạch máu dưới niêm mạc cho thấy độ nhạy, độ đặc hiệu độ chính xác của chẩn đoán phân biêt polyp tân sinh/không tân sinh lần lượt là $88 \%, 82 \%$ và $86 \%$ [6], thấp hơn kết quả nghiên cứu của Teixeira và cộng sự đánh giá 309 polyp đại trực tràng bằng NSPĐ FICE có độ nhạy, độ đặc hiệu, độ chính xác của chẩn đoán phân biệt polyp tân sinh/không tân sinh tương ứng là $99,2 \%, 94,9 \%, 98,3 \%$ [4]. Sự khác biệt có thể do sự khác biệt liên quan đến cõ̃ mẫu, đặc điểm đối tượng nghiên cứu, hoặc sự kinh nghiệm trong đọc kết quả NSPĐ FICE. Mặc dù còn có sự khác biệt với kết quả một số nghiên cứu khác nhưng NSPĐ FICE sử dụng phân loai mạch máu của Teixeira CR đã cho thấy tính hiệu quả và tin cậy trong dự đoán polyp tân sinh và không tân sinh. Kết quả nghiên cứu của chúng tôi đã cung cấp thêm bằng chứng có giá trị để làm cơ sở triển khai rộng rãi hơn hệ thống NSPĐ nhuộm màu ảo tại Việt Nam. Ngoài ra, những nghiên cứu về NSPĐ FICE trước đây chủ yếu tập trung đánh giá vào mật độ mạch máu hoặc hình thái bề mặt polyp mà chưa đánh giá sâu để mô tả hình thái mạch máu của các polyp ung thư hóa. Vì vậy, trong nghiên cứu chúng tôi muốn nhấn mạnh mô tả mô tả chi tiết đặc điểm mạch máu dưới niêm mạc của các tổn thương ung thư với đăc trưng của sự tăng sinh mạch, mạch máu trở nển bất thường, giãn rộng và mất cấu trúc mạch. Đồng thời, việc sử dụng phân loại mạch máu Teixeira cho NSPĐ FICE là dễ tiếp cận, sử dụng trong thực hành lâm sàng cho bác sỹ nội soi.

Kết quả nghiên cho thây, độ nhạy, độ đặc 
hiệu và độ chính xác của chẩn đoán polyp tân sinh/không tân sinh của NSPĐ nhuộm màu thật Crystal violet là $97,1 \%, 77,2 \%$ và $93,1 \%$. Kết quả này tương đồng với nghiên cứu Matsuda $T$ và cộng sự đã chẩn đoán phân biệt polyp tân sinh và đánh giá mức độ xâm lấn của các polyp ác tính có độ nhạy, độ đặc hiệu và độ chính xác tương ứng là $85,6 \%, 99,4 \%$ và $98,8 \%$ [7]. Kết quả nhiêu nghiên cứu khác nhau trên thế giới cho thây, độ nhạy và độ đặc đặc hiệu và độ chính xác của chẩn đoán phân biệt polyp tân sinh/không tân sinh theo phân loại Kudo dao động giữa độ nhạy (82-94\%), độ đặc hiệu (65$93 \%)$, độ chính xác (80-93\%). Ngoài ra, đánh giá mối liên quan giữa typ Vi và Vn (phân loại Kudo) và kết quả mô bệnh học cho thấy, tất cả 47 polyp có phân loại Kudo typ Vi, Vn đều có kết quả mô bệnh học tương ứng từ polyp loạn sản độ cao đến ung thư. Cụ thể, 24 polyp Kudo typ Vi có 29,2\% (7/24) polyp loạn sản độ cao, 50\% (12/24) polyp là ung thư xâm lấn chưa qua lớp dưới niêm mạc và 20,8\% (5/24) polyp là ung thư xâm lấn đã qua lớp dưới niêm mạc. Trong khi đó, 23 polyp Kudo typ Vn, đa số polyp là ung thư xâm lấn qua lớp dưới niêm mạc với $78,3 \%$ (18/23) polyp, chỉ có $21,7 \%(5 / 23)$ là ung thư xâm lấn chưa qua lớp dưới niêm mạc, và không có trường hợp polyp loạn sản độ cao.

Trong khi NSPĐ FICE găp hạn chế trong dự đoán mức độ xâm lấn với polyp ung thư, NSPĐ nhuộm màu Crystal violet được ghi nhận có khả năng dự đoán mức độ xâm lấn của polyp ung thư rất tốt. Khi đó, việc chỉ định ESD hoăc EMR để cắt bỏ polyp trong quá trình phẫu thuật sẽ chính xác và phù hợp cho bệnh nhân. Vì vậy, đối với các polyp ác tính được NSPĐ nhuộm màu Crystal violet $0,05 \%$ có kết quả phân loại Kudo typ Vi (dự đoán kết quả mô bệnh học là ung thư biểu mô trong lớp niêm mạc) sẽ có thể được chỉ định ESD hoặc EMR cắt polyp trong nội soi, còn các polyp có phân loại Kudo typ Vn (dự đoán mô bệnh học là ung thư biểu mô đã xâm lấn qua lớp dưới niểm mạc) sẽ được chỉ định phẫu thuật.

Kết quả nghiên cứu của chúng tôi cho thây có 47 polyp được chẩn đoán Kudo typ V. Trong đó, 24 polyp được phân loại hình thái lỗ niêm mạc Kudo typ Vi đều được cắt bằng $E M R / E S D$, sau đó đánh giá kết quả mô bệnh học nhận thấy: có 19 polyp $(79,2 \%)$ được điều trị thành công, có mô bệnh học là loạn sản độ cao hoặc ung thư vẫn còn trong lớp niềm mạc. Có 5 polyp $(20,8 \%)$ có kết quả mô bệnh học là ung thư xâm lấn lớp dưới niêm mạc. Tất cả những trường hợp này đều được chỉ định phẫu thuật bổ sung. Tuy nhiên, kết quả một số nghiên cứu cho thấy, với những trường hợp polyp ung thư xâm lấn lớp dưới niêm mạc với mức độ xâm lấn < 1000 m thì chỉ cần chỉ định điều trị EMR/ESD mà không cần phẫu thuật bổ sung [8]. Mặc dù vậy, đây cũng là hạn chế trong nghiên cứu của chúng tôi do chưa thể đo được chính xác mức độ xâm lấn lớp dưới niêm mac đã vượt qua mức $1000 \mu \mathrm{m}$ hay chưa, nên việc chỉ định điều trị phẫu thuật bổ sung ở các trường hợp polyp ung thư có xâm lấn lớp dưới niêm mạc là cần thiết và đảm bảo an toàn cho bệnh nhẩn.

Các phương pháp nội soi cải tiến cho phép quan sát hình ảnh có độ phân giải cao dần được áp dụng thường quy hơn trong thực hành lâm sàng. Phân tích hình thái lố niêm mạc (pit pattern) qua NSPĐ nhuộm màu Crystal violet hoặc phân tích đặc điểm mạch máu niêm mạc (capillary pattern) qua NSPĐ FICE là các kỹ thuật nội soi cho phép dự đoán kết quả mô bệnh học polyp đại trực tràng rất đáng tin cậy khi chưa cần sinh thiết hoặc phẫu thuật cắt polyp làm mô bệnh học. Điều này là rất quan trọng giúp ích cho các nhà nội soi lựa chọn phương pháp điều trị (EMR, ESD, phẫu thuật) tốt nhất cho bệnh nhân có polyp đại trực tràng.

\section{KẾT LUẬN}

Giá trị độ nhạy, độ đặc hiệu, độ chính xác trong dự đoán mô bệnh học polyp tân sinh/không tân sinh của phương pháp NSPĐ nhuộm màu ảo FICE $(92,1 \% ; 68,5 \%$ và $88,3 \%)$, NSPĐ nhuộm màu thật Crystal violet $0,05 \%$ $(97,2 \% ; 72,2 \%$ và $93,1 \%)$.

NSPĐ nhuộm màu thật Crystal violet 0,05\% với polyp có phân loại Kudo typ Vi, Vn là hữu ích cho các nhà lâm sàng trong dự đoán giữa ung thư trong niêm mạc hay ung thư xâm lấn qua lớp dưới niêm mạc.

\section{TÀI LIÊU THAM KHẢO}

\section{Bonnington S.N, Rutter M.D (2016).} Surveillance of colonic polyps: Are we getting it right? World J Gastroenterol, 22(6), 1925-1934.

2. Shussman N, Wexner S.D (2014). Colorectal polyps and polyposis syndromes. Gastroenterol Rep (Oxf), 2(1), 1-15.

3. Silva S.M, Rosa V.F, dos Santos Acn et al (2014). Influence of patient age and colorectal polyp size on histopathology. Arq Bras Cir Dig, 27(2), 109-113.

4. Teixeira C.R, Torresini R.S, Canali $C$ et al (2009). Endoscopic classification of the capillaryvessel pattern of colorectal lesions by spectral estimation technology and magnifying zoom imaging. Gastrointest Endosc, 69(3 Pt 2), 750-756.

5. Kobayashi $\mathbf{Y}$, Kudo S.E, Miyachi $H$ et al (2011). Clinical usefulness of pit patterns for 
detecting colonic lesions requiring surgical treatment. Int J Colorectal Dis, 26(12), 1531-1540.

6. Longcroft-Wheaton G.R, Higgins $B$, Bhandari $P$ (2011). Flexible spectral imaging color enhancement and indigo carmine in neoplasia diagnosis during colonoscopy: a large prospective UK series. Eur J Gastroenterol Hepatol, 23(10), 903-911.

7. Matsuda $T$, Fujii $T$, Saito $Y$ et al (2008). Efficacy of the invasive/non-invasive pattern by magnifying chromoendoscopy to estimate the depth of invasion of early colorectal neoplasms. Am J Gastroenterol, 103(11), 2700-2706.

8. Iwatate $M$, Ikumoto $T$, Sano $Y$ et al (2011). Diagnosis of neoplastic and non-neoplastic lesions and prediction of submucosal invasion of early cancer during colonoscopy. Revista Colombiana de Gastroenterologia, 26, 43-57.

\title{
KHẢO SÁT TÌNH HÌNH SỬ DUUNG KHÁNG SINH VÀ CÁC YẾU TỐ LIÊN QUAN ĐẾN HIỆU QUẢ ĐIỀU TRI VIÊM PHỔI CộNG ĐỒNG Ở TRẺ EM
}

\author{
Nguyễn Thi Nam Phong*, Nguyễn Khắc Minh*, Nguyễn Thị Tâm*, \\ Phạm Viết Tín*, Ngô Thị Nga*, Nguyễn Thị Đoan Trinh*, \\ Nguyễn Thanh Quang*, Trần Thị Thúy Nga*, Đỗ Thị Hồng Tươ**

\section{AND THE FACTORS INFLUENCING THE} \\ TREATMENT EFFECTIVENESS
}

\section{TÓM TẮT}

Đặt vấn đề: Kháng sinh là liệu pháp điều trị chính trong viêm phổi cộng đồng (VṔCĐ) ở trẻ em. Hiện nay, vi khuẩn gây VPCD thường có tỷ lệ đa kháng thuốc cao; do đó cần cập nhật tình hình sử dụng kháng sinh nhằm quản lý, đảm bảo sử dụng an toàn và hiệu quả. Mục tiêu: Phân tích tình hinh sử dụng các liệu pháp kháng sinh đơn trị và phối hợp, hiệu quả điều trị và các yếu tố liên quan đến hiệu quả điêu trị VPCĐ ở trẻ em $2-60$ tháng tuổi. Đối tượng và phương pháp nghiên cứu: Mô tả cắt ngang, hồi cứu 360 bệnh án bệnh nhi từ tháng 09/2018-09/2019. Kết quả: Liệu pháp đơn trị nhóm betalactam chiếm ưu thế $(92.6 \%)$. Trong các đơn trị, amoxicilin có tần suất sử dụng cao nhất $(25,2 \%)$. Liệu pháp phối hợp betalactam và macrolid chiếm tỳ lệ cao nhất $(53,7 \%)$ so với các phối hớp khác. Tỷ lê bệnh nhân được chỉ định kháng sinh có liều và nhịp đưa thuốc phù hợp với các hướng dâ̂n lần lướt là $81,4 \%$ và $94,4 \%$. Hiêu quả điều trị VPCĐ trong vòng 48-72 giờ đầu thành công đat $89,2 \%$. Tiền sứ bênh, mức đồ viêm phổi, tiền sứ dùng kháng sinh và tính hợp lý về liêu dùng thuốc là các yếu tố có liên quan với hiệu quả điều trị. Kết luận: Nhìn chung, việc chỉ định các liệu pháp kháng sinhh, liều và nhịp dùng thuốc tại các bệnh viện đa phần phù hợp với khuyển cáo. Xem xét các yếu tố ảnh hưởng đến hiệu quả điều trị trong vòng 48-72 giờ đầu để có thể cải thiên kết quả trên bềnh nhân.

Từ khóa: Viềm phổi cộng đồng, trẻ em, liệu pháp kháng sinh, hiệu quả điêu trị

\section{SUMMARY \\ COMMUNITY-ACQUIRED PNEUMONIA IN CHILDREN: USED ANTIMICROBIAL THERAPIES}

*Trường Đại học Kỹ thuật Y-Dược Đà Nẵng

** Đại học Y Dược Thành phố Hồ Chí Minh

Chịu trách nhiệm chính: Đỗ Thị Hồng Tươi

Email: hongtuoi@ump.edu.vn

Ngày nhận bài: 16.6 .2021

Ngày phản biên khoa họ: 13.8.2021

Ngày duyệt bài: 23.8.2021
Introduction: Antimicrobial therapies are the main treatment for Community-acquired pneumonia (CAP) in children. Nowadays, the high ratio of multidrug-resistant bacteria leads to updating the actual antibiotical usage to control and use antibiotics safely as well as effectively. Objectives: To study the use of mono and combination therapy, related factors of the effectiveness of the CAP treatment in children from 2-60 months of age. Materials and methods: A cross-sectional, retrospective study on 360 medical records of children hospitalized from September 2018 to September 2019 was conducted at some hospitals in Quang Nam province. Results and discussions: Mono-therapy with $\beta$-lactams $(92.6 \%)$ predominates over combination therapy. Among the monotherapy, amoxicillin has the highest frequency of use $(25.2 \%)$. Combination therapy with beta-lactam and macrolide accounted for the highest rate $(53.7 \%)$ compared with other combinations. The rate of antibiotic use with an appropriate dose and timing administration was $81.4 \%$ and $94.4 \%$, respectively. The success rate of CAP treatment reached $89.2 \%$ within the first $48-72$ hours. The factors influencing the effectiveness of the treatment include the history of the patient, the severity of disease, the history of antibiotic use, and the appropriateness of the dose. Conclusions: In general, the indications of antibiotic therapy, dosage, and timing administration in hospitals are mostly under current guidelines. Factors affecting treatment effectiveness within 48-72 hours should be taken into consideration to improve patient outcomes.

Keywords: Community-acquired pneumonia, children, antibiotic therapy, treatment effectiveness

\section{I. ĐĂTT VẤN ĐỀ}

Viêm phổi cộng đồng (VPCĐ) là tình trạng nhiễm khuẩn nhu mô phổi xảy ra ở ngoài bểnh viện tần suất bệnh thay đổi theo mùa [1]. Viêm phổi có thể gặp ở mọi lứa tuổi nhưng nặng nhất ở trẻ em và là nguyên nhân gây tử vong hàng đầu đối ở những bệnh nhi dưới 5 tuổi [2]. WHO 